\title{
Downstream health impacts of employment losses during the COVID-19 pandemic
}

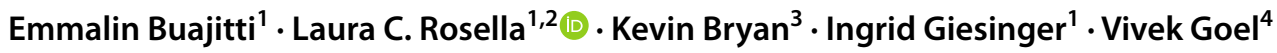

Received: 15 February 2021 / Accepted: 15 October 2021 / Published online: 7 December 2021

(C) The Author(s), under exclusive licence to The Canadian Public Health Association 2021

\begin{abstract}
Objectives The Canadian workforce has experienced significant employment losses during the COVID-19 pandemic, in part as a result of non-pharmaceutical interventions to slow COVID-19 transmission. Health consequences are likely to result from these job losses, but without historical precedent for the current economic shutdown they are challenging to plan for. Our study aimed to use population risk models to quantify potential downstream health impacts of the COVID-19 pandemic and inform public health planning to minimize future health burden.

Methods The impact of COVID-19 job losses on future premature mortality and high-resource health care utilization (HRU) was estimated using an economic model of Canadian COVID-19 lockdowns and validated population risk models. Five-year excess premature mortality and HRU were estimated by age and sex to describe employment-related health consequences of COVID-19 lockdowns in the Canadian population.

Results With federal income supplementation like the Canadian Emergency Response Benefit, we estimate that each month of economic lockdown will result in 5.6 new high-resource health care system users (HRUs), and 4.1 excess premature deaths, per 100,000, over the next 5 years. These effects were concentrated in ages 45-64, and among males 18-34. Without income supplementation, the health consequences were approximately twice as great in terms of both HRUs and premature deaths. Conclusion Employment losses associated with COVID-19 countermeasures may have downstream implications for health. Public health responses should consider financially vulnerable populations at high risk of downstream health outcomes.
\end{abstract}

\section{Résumé}

Objectifs La population active canadienne a connu d'importantes pertes d'emplois durant la pandémie de COVID-19, en partie en raison des interventions non pharmaceutiques menées pour ralentir la transmission du virus. Ces pertes d'emplois auront probablement des conséquences pour la santé, mais en l'absence d'un précédent historique au ralentissement économique actuel, il est difficile de planifier quoi faire pour atténuer ces conséquences. Notre étude visait à chiffrer les éventuels effets sanitaires de la pandémie de COVID-19 en aval à l'aide de modèles de risque pour la population et à éclairer la planification en santé publique afin de réduire le futur fardeau pour la santé.

Méthode Nous avons estimé l'impact des pertes d'emplois dues à la COVID-19 sur les chiffres futurs de mortalité prématurée et d'utilisation élevée des soins de santé (UESS) à l'aide d'un modèle économique des confinements dus à la COVID-19 au Canada et de modèles de risque pour la population validés. Nous avons estimé la surmortalité prématurée et l'UESS par âge et par sexe dans cinq ans afin de décrire les conséquences pour la santé des effets sur l'emploi des confinements dus à la COVID-19 dans la population canadienne.

Résultats Avec les mesures fédérales de supplémentation du revenu comme la Prestation canadienne d'urgence, nous estimons qu'avec chaque mois de confinement économique, il y aura 5,6 nouveaux grands usagers du système de soins de santé (GUSSS) et 4,1 décès prématurés supplémentaires pour 100000 habitants au cours des cinq prochaines années. Ces effets seront concentrés dans la tranche d'âge des 45 à 64 ans et chez les hommes de 18 à 34 ans. Sans supplémentation du revenu, les conséquences pour la santé seront environ le double, tant pour le nombre de GUSSS que de décès prématurés. Conclusion Les pertes d'emplois associées aux mesures de prévention de la COVID-19 pourraient avoir des conséquences pour la santé en aval. Les interventions de santé publique devraient donc tenir compte des populations financièrement vulnérables à risque élevé de connaître des problèmes de santé en aval.

Extended author information available on the last page of the article 
Keywords COVID-19 $\cdot$ Public health $\cdot$ Health policy $\cdot$ Employment

Mots-clés COVID-19 santé publique $\cdot$ politique de santé $\cdot$ emploi

\section{Introduction}

In the absence of established therapeutics to prevent or treat COVID-19, socially disruptive non-pharmaceutical public health interventions (NPIs) have been widely used, including social distancing, school and business closures, travel restrictions, and stay-at-home orders (Aledort et al., 2007). NPIs have demonstrated success at limiting the immediate health consequences of COVID-19 (Jüni et al., 2020). However, NPIs have significantly impacted population health, through delayed medical appointments and surgical procedures (Wiseman et al., 2020), domestic violence and child abuse (Boserup et al., 2020), mental illness (Fofana et al., 2020), increased alcohol and substance use, and decreased physical activity and increased food insecurity (Niedzwiedz et al., 2021; Wolfson \& Leung, 2020).

NPIs also had devastating consequences for global economies and workforces. In Canada, the employment rate fell 9.7\% between February and April, and almost $20 \%$ in youth aged 15 to 24 (Statistics Canada, 2020a). Because some wages in Canada continued to be paid by government subsidies (e.g., CEWS, the Canadian Emergency Wage Subsidy (Government of Canada, 2020b)) while businesses were closed to operations, the fall in active employment was likely much higher. Total hours worked fell $27.7 \%$ over the same period, despite CEWS subsidies (Statistics Canada, 2020c). These employment losses are dangerous for the financial security and public health of the Canadian population. Approximately 25-30\% of Canadians are vulnerable to extreme financial vulnerability as a result of economic lockdowns, with significant challenges to their ability to meet essential needs (Messacar \& Morissette, 2020).

Evidence is needed regarding the potential public health consequences of employment losses resulting from the COVID-19 pandemic to better respond to and mitigate future health challenges (Bavli et al., 2020). Our study leveraged an existing economic model of productivity shocks resulting from Canadian COVID-19 lockdowns, and two Population Risk Tools (PoRTs, which predict future health burden), to quantify the potential downstream health impacts of policy responses to the COVID19 pandemic in the Canadian working population over the next 5 years.

\section{Methods}

\section{Overview of models used}

This study uses three existing modelling approaches, which have been described in detail elsewhere: an economic model of Canadian COVID-19 lockdowns (Bryan et al., 2021) and two PoRTs, which predict the future prevalence of high resource utilization (Rosella et al., 2018) and premature mortality (Rosella et al., 2020). A brief overview of the models follows.

The economic model considers Canadian COVID-19 lockdowns as productivity shocks to each sector, based on how many workers in that sector are able to work from home (Blit et al., 2020; del Rio-Chanona et al., 2020). These direct shocks are propagated to all other sectors based on a production network approach considering transactions between related industries-functionally, this is based on the principle that if an upstream sector is affected (e.g., oil and gas extraction), downstream sectors (e.g., transportation) will also suffer a productivity shock. The specific coefficients are based on supply and use tables produced by Statistics Canada (StatsCan Table 36100001). The model-based estimates of employment losses were compared to observed declines in hours worked by sector from the Canadian Labour Force Survey and were found to be highly accurate; the importance of this production network-based approach is illustrated by the finding that half of COVID-19 productivity shocks result from indirect industry linkages rather than direct lockdown effects (Bryan et al., 2021).

The PoRTs are predictive risk tools developed for application to population health (Manuel et al., 2012). They were developed using routinely collected Canadian health survey data, which capture population-level estimates of risk factors including sociodemographic characteristics, health-relevant behaviours, and disease status (Rosella et al., 2018, 2020). After quantifying relationships between these features and outcome risk based on observed incidence of the health outcome in historical data, PoRTs can be used to predict the effects of changing risk exposure on outcome prevalence over time (Bilandzic \& Rosella, 2017; O'Neill et al., 2021). These models take as input the distribution of risk factors in the entire study population, and can accommodate changes to any measured variable in the model. The output of the model is the probability of the health outcome at the population level, 
based on the specified characteristics and risk factors; in our case, the probability of HRU and premature mortality based on changes to the income distribution as a result of job losses.

We combined the economic model and PoRTs to estimate the changes in high resource utilization and premature mortality resulting from 1 month of lockdown, as mediated only by job losses. First, the productivity shocks from the economic model were used to quantify job losses by sector during the specified lockdown scenario. Second, job loss probabilities were used to randomly assign income losses to households in the Canadian population, again based on the specific scenario (i.e., income supplementation versus none). Finally, the new income distribution following specified job losses was passed to the PoRTs to estimate the number of HRUs and premature deaths that would be observed in the next 5 years under the conditions specified; these numbers were compared to the baseline values to quantify the change in HRU and premature mortality as a result of 1 month of lockdowns. This analysis workflow is shown in Fig. 1.

\section{Data and definitions}

Population data were from the 2013-2014 cycle of the Canadian Community Health Survey (CCHS). The CCHS is a cross-sectional survey conducted by Statistics Canada on an ongoing basis. It is representative of the Canadian non-institutionalized population aged 12 and older; the detailed survey methodology has been described elsewhere (Beland, 2002).

The study population included all CCHS respondents in the 2013-2014 cycle aged 18-74 at interview date. This age range corresponds to age limits from the population risk tools used, and aligns with use of the CCHS questionnaire; only respondents ages 15 to 75 are asked about their employment status at interview.

\section{Employment}

A CCHS respondent was defined as being employed if they responded 'yes' to either of the following questions: "Last week, did you work at a job or business?" or "Last week, did you have a job or business from which you were absent?".

All employed CCHS respondents are asked to describe the kind of business, industry, or service of their workplace. These responses were coded according to the North American Industry Classification System (NAICS) 2007 and categorized into industry groups according to the first three digits of the NAICS code.

\section{Income}

All CCHS respondents are asked to report their total household income in the 12 months prior to interview. Respondents were ranked into national income deciles and quintiles according to the ratio of their self-reported household income to Statistics Canada's Low Income Cut Off (LICO). LICO is assigned according to geography of residence and household size, and accounts for regional differences in cost of living and per-person equivalences

\section{Health outcomes}

High resource users (HRUs) are defined, generally, as individuals who account for a large amount of health care system spending. HRUs are a meaningful group in the context of health policy, particularly in single-payer settings; in Ontario, Canada, the top 5\% of cost-consuming health care system users account for more than $50 \%$ of all system costs (Rais et al., 2013; Wodchis et al., 2016). High resource utilization also has important implications for population health and morbidity, since HRUs are likely to have multiple chronic conditions and report poor general health (Reid et al., 2003; Rosella et al., 2014). For this study, HRUs were defined using historical data on health system costs between 2005 and 2013 in Ontario, Canada. HRUs made up $5 \%$ of cost-incurring users in that time period; the number of HRUs in future years is relative to this historical cutoff and increases as health system costs rise.

Premature deaths were defined as deaths between the ages of 18 and 74. This definition has been consistently used to

Fig. 1 Summary of models used

Economic Model

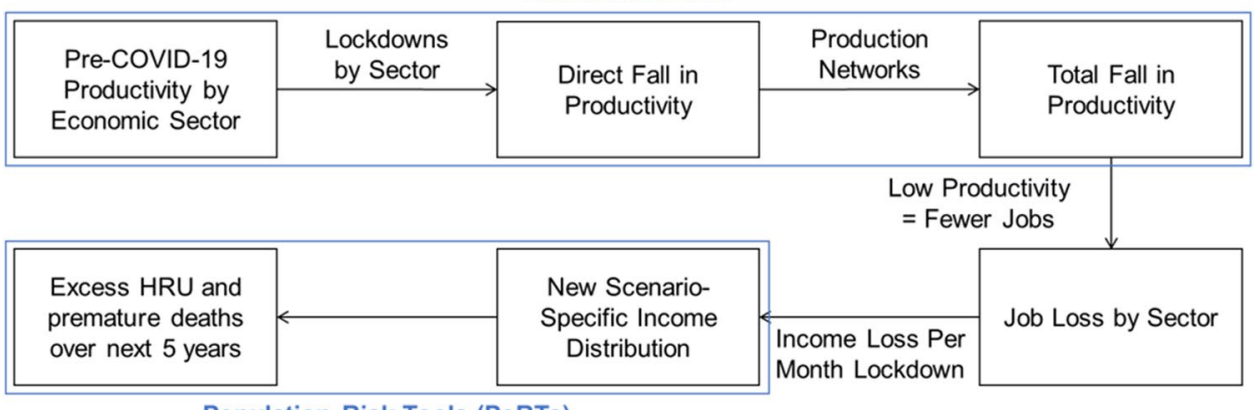

Population Risk Tools (PoRTs) 
define premature mortality in Canada (Canadian Institute for Health Information, 2012) and other jurisdictions (Remington et al., 2013; Thomas et al., 2010). Premature mortality is a robust measure of population health, as many deaths before the age of 75 are preventable through appropriate medical, public health, or other policy intervention.

\section{Statistical analysis}

\section{Job losses and income effects}

The economic model (Bryan et al., 2021) was used to estimate job loss probabilities, by sector, for the Canadian workforce as a result of each lockdown scenario (assumed to last 1 month). These probabilities were used to randomize specific CCHS respondents to job loss, and an associated loss in income within age groups. Table 1 shows the specific change in income decile that is assumed by each scenario (with or without income supplementation).

\section{Downstream health impacts}

According to the new income distribution resulting from each employment loss scenario, future high resource utilization was estimated using HRUPoRT (Rosella et al., 2018). HRUPoRT was used to estimate the number of HRUs that would result in each 1-month employment loss scenario in a 5-year follow-up period, for each sex and age group. Each scenario was also compared to the baseline scenario to identify excess HRU risk associated with 1 month of employment loss. One month was chosen to reflect the period where there was a major lockdown, which was the case in March 2020. This contrasts with partial lockdowns, which were in place throughout the pandemic where many businesses remained open. We additionally include a sensitivity analysis using a 3-month lockdown.

Future premature mortality risk was estimated using PreMPoRT (Rosella et al., 2020). PreMPoRT was used to estimate the number of premature deaths that would result over the same 5-year follow-up period, for each 1-month employment loss scenario. Excess premature deaths were estimated by comparing to the baseline scenario.

\section{Overview of scenarios}

Three scenarios were specified to reflect a range of employment and income scenarios in the Canadian population. As specified, the scenarios assume that income reductions would persist over a 1-month lockdown period and not beyond.

\section{Baseline scenario: No change to employment status or income distribution}

In the baseline scenario, 5-year estimates of HRUs and premature deaths were estimated using the household income reported by CCHS respondents at interview.

\section{Scenario 1: Full lockdown scenario with no income supplementation}

In Scenario 1, all non-essential sectors whose workforces are unable to work from home are closed. This is a direct representation of the employment effects of the lockdown experienced in April 2020, which resulted in 27.7\% fewer hours worked (Statistics Canada, 2020b). This scenario assumes

Table 1 Modelled income losses by CCHS household income quintile

\begin{tabular}{|c|c|c|c|c|c|}
\hline $\begin{array}{l}\text { Household } \\
\text { income } \\
\text { decile }\end{array}$ & $\begin{array}{l}\text { Median annual house- } \\
\text { hold income }(\$ 1000 \mathrm{~s})^{\text {a }}\end{array}$ & $\begin{array}{l}\text { Median household per- } \\
\text { sonal income }(\$ 1000 \mathrm{~s})^{\mathrm{a}}\end{array}$ & $\begin{array}{l}\text { Annualized Canadian } \\
\text { Emergency Response } \\
\text { Benefit }(\mathrm{CERB}) \text { entitle- } \\
\text { ment }(\$ 1000 \mathrm{~s})\end{array}$ & $\begin{array}{l}\text { Household income } \\
\text { decile after lost } \\
\text { employment }^{\mathrm{b}}\end{array}$ & $\begin{array}{l}\text { Household income decile } \\
\text { after lost employment, } \\
\text { with } \mathrm{CERB}^{\mathrm{c}}\end{array}$ \\
\hline 1 & 13 & 11.5 & 12 & 1 & 1 \\
\hline 2 & 22 & 14 & 12 & 1 & 2 \\
\hline 3 & 30 & 18 & 12 & 1 & 2 \\
\hline 4 & 40 & 24 & 12 & 1 & 3 \\
\hline 5 & 50 & 28 & 12 & 2 & 3 \\
\hline 6 & 60 & 33 & 12 & 3 & 4 \\
\hline 7 & 72 & 40 & 12 & 3 & 4 \\
\hline 8 & 90 & 48 & 12 & 4 & 5 \\
\hline 9 & 100 & 55 & 12 & 4 & 6 \\
\hline 10 & 165 & 80 & 12 & 8 & 9 \\
\hline
\end{tabular}

${ }^{\text {a }}$ Source: 2013-2014 Canadian Community Health Survey

${ }^{\mathrm{b}}$ Used in Scenarios 1 and 3

${ }^{\mathrm{c}}$ Used in Scenario 2 
that income losses are not supplemented by social benefits, such as employment insurance or emergency benefits.

\section{Scenario 2: Full lockdown with income supplementation to unemployed}

In Scenario 2, the same employment losses are experienced as in Scenario 1. However, income losses are offset by income supports. Specifically, each unemployed worker receives $\$ 2000$, equivalent to the maximum 4-week entitlement of the Canadian Emergency Response Benefit (CERB) (Government of Canada, 2020a). CERB was available to many Canadian workers who were unable to work as a result of the COVID-19 pandemic; this scenario assumes that all eligible workers would receive the maximum entitlement for the duration of their unemployment.

\section{Scenario 3: Downstream lockdown scenario (upstream sectors remain open)}

In Scenario 3, selected upstream sectors are allowed to remain open - this would minimize economic (GDP) consequences compared to a full lockdown, per Bryan et al. (2021). Specifically, manufacturing, mining, transportation, and wholesale industries are allowed to remain open in this scenario, while downstream and public-facing sectors such as retail, food and beverage, and hospitality businesses are required to close. As with Scenario 1, this scenario assumes no income supplementation is provided.

\section{Results}

\section{Baseline population}

From the 2013-2014 CCHS cycle, 100,721 respondents were between the ages of 18 and 74 . This survey population is representative of the Canadian population aged 18 to 74 (weighted $n=25,561,035$ ). Within this population, $68.2 \%$ were classified as employed (weighted $n=17,444,906$ ) (Table 2). The number and percent of employed CCHS respondents varied by age and sex, between $15.4 \%$ (females ages 65 to 74 ) and $87.2 \%$ (males ages 35 to 44 ). In general, males were more likely to be employed than females, and employment decreased with age after the 35 to 44 age group.

\section{Job losses}

Table 3 shows the age and sex distribution of job losses in each modelled scenario. Unsurprisingly, job losses were higher in the full lockdown scenario (26.1\%) than in the downstream-focused lockdown scenario (14.1\%). Job losses were generally concentrated among young workers (aged 18-34) and among older males (aged 55-74).

\section{High resource utilization}

HRUPoRT estimates of high resource utilization are shown in Table 4. In the baseline scenario, HRUPoRT predicts 1.4 million Canadians will transition to HRU status over 5 years. These individuals make up 5.6\% of the population ages 18 to 74 . HRUs are more likely to be male than female, and likelihood of HRU status increases with age.

Scenario 1, which describes a full lockdown lasting 1 month with no income support, is estimated to result in 2568 excess HRUs over the next 5 years. These HRUs will be concentrated in middle ages, particularly among females aged 45-64 and males aged 55-64 (Table 4).

Both Scenario 2, which includes the same lockdown but with income support of $\$ 2000$ per month, and Scenario 3, which keeps upstream sectors open, are protective against future HRUs. Scenario 2 resulted in the fewest new HRUs
Table 2 Age and sex distribution of baseline population (Canadian population aged 18 to 74)

\begin{tabular}{lllrrl}
\hline Sex & Age group & $\begin{array}{l}\text { Unweighted } N \\
\text { (respondents) }\end{array}$ & $\begin{array}{l}\text { Weighted } N \\
\text { (population) }\end{array}$ & \# Employed & \% Employed \\
\hline Females & $18-34$ & 12,985 & $3,911,971$ & $2,773,310$ & 70.9 \\
Females & $35-44$ & 7966 & $2,386,527$ & $1,823,926$ & 76.4 \\
Females & $45-54$ & 8679 & $2,547,394$ & $2,013,982$ & 79.1 \\
Females & $55-64$ & 13,676 & $2,380,951$ & $1,354,734$ & 56.9 \\
Females & $65-74$ & 11,901 & $1,640,181$ & 252,037 & 15.4 \\
Males & $18-34$ & 11,067 & $4,016,149$ & $3,133,130$ & 78 \\
Males & $35-44$ & 6949 & $2,323,128$ & $2,025,231$ & 87.2 \\
Males & $45-54$ & 7260 & $2,494,315$ & $2,073,898$ & 83.1 \\
Males & $55-64$ & 10,964 & $2,378,034$ & $1,602,479$ & 67.4 \\
Males & $65-74$ & 9274 & $1,482,385$ & 392,180 & 26.5 \\
Total & & 100,721 & $25,561,035$ & $17,444,906$ & 68.2 \\
\hline
\end{tabular}

${ }^{a}$ Employment defined as having a job in the week prior to CCHS interview, according to self-report 
Table 3 Job losses as a result of lockdown, Canadian population aged 18 to 74 by age and sex

\begin{tabular}{llllll}
\hline Sex & Age group & Population (1000s) & \multicolumn{4}{l}{$\%$ of jobs lost, by scenario } \\
\cline { 5 - 6 } & & & Scenario 1 & Scenario 2 & Scenario 3 $^{\text {b }}$ \\
\hline Females & $18-34$ & 3894 & 28.2 & 28.2 & 13.1 \\
Females & $35-44$ & 2377 & 21.0 & 21.0 & 13.5 \\
Females & $45-54$ & 2540 & 26.2 & 26.2 & 15.0 \\
Females & $55-64$ & 2375 & 24.7 & 24.7 & 18.3 \\
Females & $65-74$ & 1637 & 26.5 & 26.5 & 9.1 \\
Males & $18-34$ & 3998 & 32.4 & 32.4 & 12.5 \\
Males & $35-44$ & 2313 & 25.9 & 25.9 & 10.6 \\
Males & $45-54$ & 2485 & 15.6 & 15.6 & 15.8 \\
Males & $55-64$ & 2371 & 30.4 & 30.4 & 15.3 \\
Males & $65-74$ & 1479 & 28.9 & 28.9 & 25.6 \\
Total & & 25,470 & 26.1 & 26.1 & 14.1 \\
\hline
\end{tabular}

${ }^{a}$ Scenario 1: Full lockdown scenario with no income supplementation

${ }^{\mathrm{b}}$ Scenario 2: Full lockdown scenario with income supplementation (CERB) to unemployed

${ }^{\mathrm{c}}$ Scenario 3: Downstream lockdown scenario (upstream sectors remain open) compared to baseline, with 1415, while Scenario 3 resulted in 1529 new HRUs. Both of these scenarios significantly decreased the burden of future HRUs among females aged 45-64 and males ages 55-64 compared to Scenario 1.

\section{Premature mortality}

PreMPoRT estimates of premature mortality are shown in Table 5. In the baseline scenario, PreMPoRT estimates approximately 880,000 premature deaths over 5 years, accounting for $3.5 \%$ of the Canadian population aged 18 to 74 . Risk of premature mortality is greater for males than for females. The probability of premature mortality generally increases with age, although it is higher in the 18 to 34 age category than between ages 35 and 44, likely driven by injury-related deaths.

In the absence of financial support, the full lockdown scenario (Scenario 1) is estimated to result in 1885 excess premature deaths in the next 5 years. PreMPoRT predicts these excess deaths will be concentrated among males, particularly in young males aged 18 to 34 (Table 5). As with HRUs, excess premature deaths are also expected to be high among those aged 45-54, particularly males (Table 5).

Both income-supplemented full lockdown (Scenario 2) and downstream lockdowns (Scenario 3) are predicted by PreMPoRT

Table 4 High resource user (HRU) estimates by age group and sex in the Canadian population aged 18 to 74 , according to employment loss scenario

\begin{tabular}{|c|c|c|c|c|c|c|c|c|c|c|}
\hline \multirow[t]{2}{*}{ Sex } & \multirow[t]{2}{*}{ Age group } & \multirow{2}{*}{$\begin{array}{l}\text { Population } \\
(1000 \mathrm{~s})\end{array}$} & \multicolumn{2}{|l|}{ Baseline } & \multicolumn{2}{|l|}{ Scenario $1^{\mathrm{a}}$} & \multicolumn{2}{|l|}{ Scenario $2^{\mathrm{b}}$} & \multicolumn{2}{|l|}{ Scenario $3^{c}$} \\
\hline & & & HRU & HRU per $100 \mathrm{k}$ & New HRU & $\begin{array}{l}\text { New HRU } \\
\text { per } 100 \mathrm{k}\end{array}$ & New HRU & $\begin{array}{l}\text { New HRU } \\
\text { per } 100 \mathrm{k}\end{array}$ & New HRU & $\begin{array}{l}\text { New HRU } \\
\text { per } 100 \mathrm{k}\end{array}$ \\
\hline Females & $18-34$ & 3894 & 40,115 & 1030.2 & 114 & 2.9 & 51 & 1.3 & 51 & 1.3 \\
\hline Females & $35-44$ & 2377 & 46,274 & 1946.5 & 101 & 4.3 & 49 & 2.1 & 89 & 3.7 \\
\hline Females & $45-54$ & 2540 & 112,651 & 4435.9 & 447 & 17.6 & 242 & 9.5 & 192 & 7.6 \\
\hline Females & $55-64$ & 2375 & 211,477 & 8905.9 & 371 & 15.6 & 200 & 8.4 & 168 & 7.1 \\
\hline Females & $65-74$ & 1637 & 247,023 & $15,086.3$ & 91 & 5.5 & 29 & 1.8 & 39 & 2.4 \\
\hline Males & $18-34$ & 3998 & 50,154 & 1254.4 & 158 & 3.9 & 78 & 1.9 & 77 & 1.9 \\
\hline Males & $35-44$ & 2313 & 55,233 & 2387.9 & 171 & 7.4 & 77 & 3.3 & 92 & 4.0 \\
\hline Males & $45-54$ & 2485 & 134,031 & 5393.0 & 318 & 12.8 & 197 & 7.9 & 236 & 9.5 \\
\hline Males & $55-64$ & 2371 & 256,085 & $10,801.6$ & 586 & 24.7 & 351 & 14.8 & 406 & 17.1 \\
\hline Males & $65-74$ & 1479 & 270,662 & $18,294.9$ & 211 & 14.3 & 142 & 9.6 & 179 & 12.1 \\
\hline Total & & 25,470 & $1,423,705$ & 5589.8 & 2568 & 10.1 & 1415 & 5.6 & 1529 & 6.0 \\
\hline
\end{tabular}

${ }^{a}$ Scenario 1: Full lockdown scenario with no income supplementation

${ }^{\mathrm{b}}$ Scenario 2: Full lockdown scenario with income supplementation (CERB) to unemployed

c Scenario 3: "Optimized" lockdown scenario (upstream sectors remain open) 


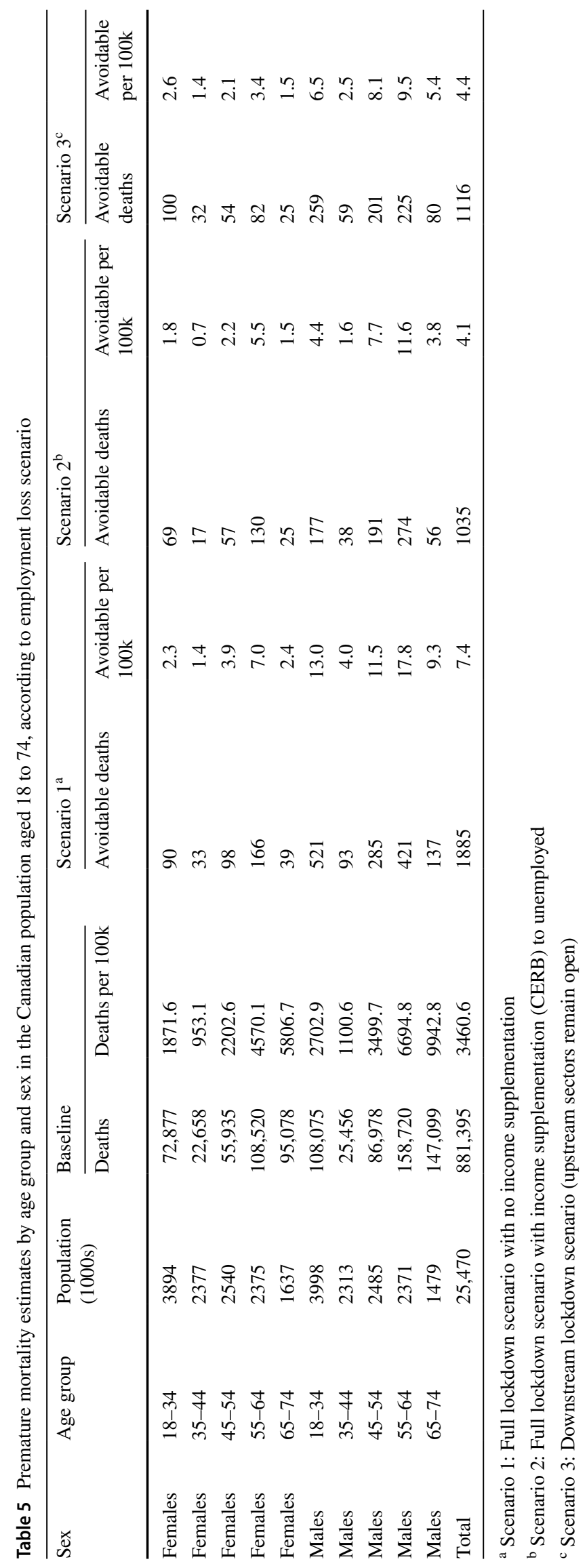


to be protective against excess premature mortality. Scenario 2 resulted in 1035 excess deaths compared to baseline, while Scenario 3 resulted in 1116 more deaths than baseline. Compared to Scenario 1, the benefits appear to be concentrated among males aged 18 to 34, who experienced 13.0 excess premature deaths per 100,000 in Scenario 1, 4.4 excess deaths per 100,000 in Scenario 2 , and 6.5 excess deaths per 100,000 in Scenario 3.

\section{Sensitivity analysis}

We additionally estimated the effects of all three scenarios based on a lockdown lasting 3 months, rather than 1; the results of this analysis are shown in Supplemental Tables S1 (HRU) and S2 (premature mortality). Overall, the effects of 3-month lockdowns were somewhat, but not strictly, additive. Specifically, for the no-income-supplementation scenarios, the number of excess HRUs was 2.7 times greater for a 3-month lockdown versus a 1-month lockdown, whereas premature mortality risk was 3.4 times as great for a 3-month lockdown (Tables S1 and S2). Income-supplemented scenarios were less additive, with 2.5 times the risk of HRU and 3.0 times the risk of premature mortality. The reason for this non-additivity is that the PoRTs do not assume income to have a linear effect on risk of HRU or premature death; thus, risks associated with a 3-month unemployment period are not a simple linear extrapolation of 1-month risks.

\section{Discussion}

\section{Interpreting these results}

We found a meaningful impact on excess HRU and premature mortality based on economic outcomes. The population impact of these impacts should be interpreted in the context of some uncertainties that exist. In a relative sense, 2568 excess HRUs and 1885 excess premature deaths each represent only about a $1 \%$ increase over the baseline values. In the context of broader risks posed by the COVID-19 pandemic, lockdowns were successful at preventing greater harms. On the other hand, these estimates correspond to an isolated 1-month lockdown period for which there are no spillover economic effects. We would expect there to be some cumulative effect of longer lockdowns, as demonstrated by the results of the sensitivity analysis, as well as ongoing productivity impacts in the post-lockdown period. There is still value in estimating these modest future effects, as the population health harms related to lockdown-induced job losses are likely to affect different subpopulations, such as essential workers or those in precarious jobs.

\section{Key findings}

Employment loss related to COVID-19 policy responses could result in downstream health impacts for the Canadian population in the next 5 years. These population impacts are in the form of both morbidity and mortality.

The age distribution of high resource utilization and premature mortality outcomes modelled in these employment loss scenarios is inverse to the age distribution of deaths from COVID-19 infection (Dowd et al., 2020). The predicted deaths consequent to COVID-19-related job loss occur earlier in life than deaths from COVID-19 itself, resulting in a greater number of potential years of life lost (Romeder \& McWhinnie, 1977). This important indicator of public health impact (Canadian Institute for Health Information, 2016) should be considered in policy responses.

\section{Limitations}

\section{Data limitations}

This analysis underestimates health consequences of COVID-19-related employment loss in the lowest income groups. These individuals may lose employment, but cannot be assigned any income loss because they are already in the lowest income group. Thus the effects of unemployment in low-income populations are likely underestimated by this analysis.

The analysis was also limited by use of self-reported interview data. Specifically, income may be misclassified in selfreported data; government transfers in particular tend to be undervalued in survey-derived income estimates (Meyer et al., 2009). Reporting of wages and salaries, which is of greater importance to this analysis, is generally more accurate (Moore $\&$ Welniak, 2000). The CCHS data used also do not distinguish between long-term income patterns and short-term earnings; household income is determined on the basis of the 12 months prior to interview only. Short-term income shocks as a result of lost employment may not confer the same health effects as longer-term earnings, which this analysis cannot account for. However, unemployment during economic downturns does impact future employment and health, in particular among youth (Marmot et al., 2013). For example, those graduating during a recession not only have lower income employment the year they enter the labour market, but also lower income as much as a decade later due to difficulties switching to more productive, higher-paying firms (Oreopoulos et al., 2012).

\section{Model limitations}

The models we used were based on historical data, which may not reflect morbidity and mortality in the coming years if there are sudden or major changes in health patterns; for instance, major health care disruptions as a result of COVID-19 responses are likely to influence the profile of a high resource user or premature decedent, based on changes in the quality and integration of care received. In 
an extreme case, this analysis could greatly overestimate the number of future HRUs if patients are discouraged from seeking care to meet their needs. However, these changes are more likely to be shorter term and it is unlikely that these disruptions would change the pattern when observing over a 5-year period. The extreme example cited, for instance, is unlikely as many efforts are being made to reach those who may have had a gap in care as part of COVID-19 recovery efforts.

The pre-specification (based on prior work) of model inputs and outputs is also of consequence to our ability to fully capture downstream health effects that will result from the COVID-19 pandemic. First, the health outcomes considered were estimated only for a 5-year time period, which is not likely to capture all adverse health outcomes based on evidence from past economic crises (Chowdhury et al., 2013; Stuckler et al., 2009). Second, because of the specific construction of PoRT inputs (which rely on risk factor distributions), and our choice to model employment losses as income changes only, we have also not accounted for health effects of job losses independent of income effects-for example, mental health consequences of unemploymentand likely estimate the health consequences of unemployment somewhat narrowly as a result.

Third, our approach is limited in the ability to quantify uncertainty in the traditional sense. While we expect our results, which are based on data representative of most of the Canadian population, to be statistically stable, they may be sensitive to our modelling choices (for instance, the change in income associated with job loss and income supplementation). We have presented a range of scenarios to reflect the range of possible outcomes and this uncertainty. Statistical uncertainty reflected by the sampling is small given the large sample, does not reflect the uncertainty in estimates, and may give a false sense of precision. Instead, we present the range of scenarios in order to reflect the uncertainty of the different assumptions as a more robust way to communicate this uncertainty.

\section{Public health implications}

Considering the health outcomes of population subgroups is imperative during economic downturn. Outcomes may appear to be static in the population as a whole, while masking the specific harms experienced by subpopulations. Policy responses to future pandemics should consider these financially vulnerable populations alongside those who are at high risk of adverse outcomes from COVID-19 itself, including additional support for those who have experienced significant economic impacts.

Early indicators suggested the economic impact of COVID-19 would be incurred by similar subgroups as those that bore the burden of prior economic crises
(Kaplan, 2012; Statistics Canada, 2020a). Among the most vulnerable were those likely to experience unemployment but without the financial savings or support systems to carry them through periods of uncertainty (Marmot et al., 2013; Messacar \& Morissette, 2020). This includes the precariously employed, low-wage workers, recent immigrants, Indigenous workers living off-reserve, and young workers. It is notable that many of these same groups also faced a greater burden of COVID-19 itself, which in Canada disproportionately affected areas with low socioeconomic status and large immigrant populations (Choi $\&$ Denice, 2020).

Youth may experience a disproportionate long-term effect on their future employment and earnings (Marmot et al., 2013). Early- and mid-career unemployment are associated with greater increases in mortality risk as compared to late-career unemployment (Roelfs et al., 2011). These mortality risks may escalate with time, as health effects of unemployment can be long-lasting (Chowdhury et al., 2013; Stuckler et al., 2010). The potential years of life lost associated with deaths in this group would be immense, and must be carefully considered.

\section{Policy responses}

Policy response is vital to recovery; the approach may mitigate or exacerbate the impact on health and inequalities. Our analyses suggest protective effects of income supplementation, such as via CERB, which is supported by evidence in the literature. Findings from a nationally representative Canadian sample demonstrated the important role of employment benefits in offsetting negative health consequences among the unemployed (Shahidi et al., 2019). These positive effects were greatest among those with lower income and less education, with no effect observed among those in higher income and highly educated groups.

Introducing programs (such as Active Labour Market Policies) where possible to maintain employment and enable re-employment may be protective for future health (Stuckler et al., 2010). Targeting those with early career job loss, or transitioning from school to work, may mitigate the long-term effects of unemployment on this subgroup (Chowdhury et al., 2013; Wahlbeck \& McDaid, 2012).

Social spending may mitigate the economic and social impact of the current crisis, and contribute to economic recovery through boosting demand (Chowdhury et al., 2013). Contractionary austerity policy and the premature removal of stimulus may jeopardize economic recovery and introduce an associated downstream impact on health. However, prolonged stimulus may result in large deficits and may 
necessitate reductions to future social spending, which could exacerbate downstream health outcomes. Where spending reductions are necessary, health equity impact assessments should be utilized to prioritize spending, maximizing health outcomes, and prevent the widening of health inequalities (Marmot et al., 2013).

\section{Conclusion}

Downstream health impacts of the COVID-19 pandemic are inevitable, given the scale of economic intervention that was required to slow transmission of the virus. These estimates of future premature mortality and high resource utilization in the Canadian population demonstrate that employment losses from COVID-19 may impact public health in terms of both morbidity and mortality. COVID-19 recovery decisions, and decision-making around future pandemics, should consider these potential impacts to protect workers and families from undue harm.

\section{Contributions to knowledge}

What does this study add to existing knowledge?

- This study offers novel insight into potential longterm public health consequences of COVID-19 policy responses.

- Our findings suggest that in addition to the real health impacts of the COVID-19 pandemic, there are indirect health impacts among those experiencing COVID-19-related job losses.

- Our findings add value by offering policy-relevant insights for those affected by job losses, which will continue to be highly relevant for public health planning as COVID-19 recovery proceeds.

What are the key implications for public health interventions, practice or policy?

- Our study motivates important considerations for public health planning through and beyond the COVID-19 pandemic.

- Combined with existing evidence regarding the relationship between COVID-19 policy responses and unemployment, and unemployment and longer-term health, our study demonstrates that public health responses to COVID-19 should consider financially vulnerable populations at high risk of downstream health outcomes alongside those who are at high risk of adverse outcomes from COVID-19 itself.
Supplementary Information The online version contains supplementary material available at https://doi.org/10.17269/ s41997-021-00588-3.

Author contributions EB, LR, and VG led the study design. EB and IG completed the literature review. EB and KB collected the data. EB conducted the data analysis and prepared figures. EB, LR, and IG wrote the first draft of the manuscript. All the authors contributed to the interpretation of the results and reviewed the final manuscript.

Funding This study was funded by the University of Toronto I'Anson Fund (FRN \#72059101). The funder had no role in study design, analysis, interpretation, or the writing or decision to submit the manuscript for publication.

Data availability The datasets used and/or analyzed during the current study are available from the corresponding author on reasonable request.

\section{Declarations}

Conflict of interest The authors declare no competing interests.

Ethics approval Not applicable.

Consent to participate Not applicable.

Consent for publication Not applicable.

\section{References}

Aledort, J. E., Lurie, N., Wasserman, J., \& Bozzette, S. A. (2007). Nonpharmaceutical public health interventions for pandemic influenza: An evaluation of the evidence base. BMC Public Health, 7, 208-208. https://doi.org/10.1186/1471-2458-7-208

Bavli, I., Sutton, B., \& Galea, S. (2020). Harms of public health interventions against COVID-19 must not be ignored. BMJ, 371, m4074. https://doi.org/10.1136/bmj.m4074

Beland, Y. (2002). Canadian community health survey-methodological overview. Health Reports, 13(3), 9-14.

Bilandzic, A., \& Rosella, L. (2017). The cost of diabetes in Canada over 10 years: Applying attributable health care costs to a diabetes incidence prediction model. Health Promotion and Chronic Disease Prevention in Canada, 37(2), 49-53. https://doi.org/10. 24095/hpcdp.37.2.03

Blit, J., Skuterud, M., \& Veall, M. R. (2020). The pandemic and shortrun changes in output, hours worked and labour productivity: Canadian evidence by industry. International Productivity Monitor (39), 16-32.

Boserup, B., McKenney, M., \& Elkbuli, A. (2020). Alarming trends in US domestic violence during the COVID-19 pandemic. The American Journal of Emergency Medicine, 38(12), 2753-2755.

Bryan, K. A., Buajitti, E., Rosella, L. C., \& Goel, V. (2021). The economic and long-term health consequences of Canadian COVID-19 Lockdowns. Canadian Public Policy(aop), e2020134.

Canadian Institute for Health Information. (2012). Health indicators 2012. Retrieved from Ottawa, ON.

Canadian Institute for Health Information. (2016). Canada's international health system performance over 50 years: Examining potential years of life lost. Retrieved from Ottawa, ON 
Choi, K., \& Denice, P. (2020). Neighbourhood SES and the COVID-19 pandemic. SocArXIV. Retrieved from https://osf.io/preprints/socar xiv/3xg5q/. Accessed 7 Dec 2020.

Chowdhury, A., Islam, I., \& Lee, D. (2013). The Great Recession, jobs and social crises: Policies matter. International Journal of Social Economics, 40(3), 220-245. https://doi.org/10.1108/03068 291311291518

del Rio-Chanona, R. M., Mealy, P., Pichler, A., Lafond, F., \& Farmer, J. D. (2020). Supply and demand shocks in the COVID-19 pandemic: An industry and occupation perspective. Oxford Review of Economic Policy, 36(Supplement_1), S94-S137.

Dowd, J. B., Andriano, L., Brazel, D. M., Rotondi, V., Block, P., Ding, X., \& ... Mills, M. C. (2020). Demographic science aids in understanding the spread and fatality rates of COVID-19. Proceedings of the National Academy of Sciences, 117(18), 9696. https://doi. org/10.1073/pnas.2004911117

Fofana, N. K., Latif, F., Sarfraz, S., Bashir, M. F., \& Komal, B. (2020). Fear and agony of the pandemic leading to stress and mental illness: An emerging crisis in the novel coronavirus (COVID-19) outbreak. Psychiatry Research, 291, 113230.

Government of Canada. (2020a). Canada Emergency Response Benefit (CERB). Retrieved from https://www.canada.ca/en/services/benef its/ei/cerb-application.html. Accessed 7 Dec 2020.

Government of Canada. (2020b). Canadian Emergency Wage Subsidy (CEWS). Retrieved from https://www.canada.ca/en/revenueagency/services/subsidy/emergency-wage-subsidy.html. Accessed 7 Dec 2020.

Jüni, P., Rothenbühler, M., Bobos, P., Thorpe, K. E., da Costa, B. R., Fisman, D. N., ... Gesink, D. (2020). Impact of climate and public health interventions on the COVID-19 pandemic: A prospective cohort study. Canadian Medical Association Journal, cmaj.200920. https://doi.org/10.1503/cmaj.200920

Kaplan, G. A. (2012). Economic crises: Some thoughts on why, when and where they (might) matter for health-a tale of three countries. Social Science \& Medicine (1982), 74(5), 643-646. https://doi. org/10.1016/j.socscimed.2011.12.013

Manuel, D. G., Rosella, L. C., Hennessy, D., Sanmartin, C., \& Wilson, K. (2012). Predictive risk algorithms in a population setting: An overview. Journal of Epidemiology and Community Health, 66(10), 859. https://doi.org/10.1136/jech-2012-200971

Marmot, M., Bloomer, E., \& Goldblatt, P. (2013). The role of social determinants in tackling health objectives in a context of economic crisis. Public Health Reviews, 35(1), 9. https://doi.org/10. 1007/BF03391694

Messacar, D., \& Morissette, R. (2020). Work interruptions and financial vulnerability. Retrieved from Ottawa, Ontario

Meyer, B. D., Mok, W. K., \& Sullivan, J. X. (2009). The under-reporting of transfers in household surveys: Its nature and consequences (0898-2937). Retrieved from

Moore, J. C., \& Welniak, E. J. (2000). Income measurement error in surveys: A review. Journal of Official Statistics, 16(4), 331.

Niedzwiedz, C. L., Green, M. J., Benzeval, M., Campbell, D., Craig, P., Demou, E., \& ... Katikireddi, S. V. (2021). Mental health and health behaviours before and during the initial phase of the COVID-19 lockdown: Longitudinal analyses of the UK Household Longitudinal Study. Journal of Epidemiology and Community Health, 75(3), 224. https://doi.org/10.1136/jech-2020-215060

O’Neill, M., Kornas, K., Wodchis, W. P., \& Rosella, L. C. (2021). Estimating population benefits of prevention approaches using a risk tool: High resource users in Ontario, Canada. Healthcare Policy = Politiques de sante, 16(3), 51-66. https://doi.org/10. 12927/hcpol.2021.26433

Oreopoulos, P., von Wachter, T., \& Heisz, A. (2012). The short- and long-term career effects of graduating in a recession. American Economic Journal: Applied Economics, 4(1), 1-29. https://doi. org/10.1257/app.4.1.1
Rais, S., Nazerian, A., Ardal, S., Chechulin, Y., Bains, N., \& Malikov, K. (2013). High-cost users of Ontario's healthcare services. Healthcare Policy = Politiques de sante, 9(1), 44-51. Retrieved from https://pubmed.ncbi.nlm.nih.gov/23968673 https://www. ncbi.nlm.nih.gov/pmc/articles/PMC3999548/. Accessed 7 Dec 2020.

Reid, R., Evans, R., Barer, M., Sheps, S., Kerluke, K., McGrail, K., \& ... Pagliccia, N. (2003). Conspicuous consumption: Characterizing high users of physician services in one Canadian province. Journal of Health Services Research \& Policy, 8(4), 215-224. https://doi.org/10.1258/135581903322403281

Remington, P. L., Catlin, B. B., \& Kindig, D. A. (2013). Monitoring progress in population health: Trends in premature death rates. Preventing Chronic Disease, 10, E214-E214. https://doi.org/10. 5888/pcd10.130210

Roelfs, D. J., Shor, E., Davidson, K. W., \& Schwartz, J. E. (2011). Losing life and livelihood: A systematic review and meta-analysis of unemployment and all-cause mortality. Social Science \& Medicine, 72(6), 840-854. https://doi.org/10.1016/j.socscimed. 2011.01.005

Romeder, J. M., \& McWhinnie, J. R. (1977). Potential years of life lost between ages 1 and 70: An indicator of premature mortality for health planning*. International Journal of Epidemiology, 6(2), 143-151. https://doi.org/10.1093/ije/6.2.143

Rosella, L. C., Fitzpatrick, T., Wodchis, W. P., Calzavara, A., Manson, H., \& Goel, V. (2014). High-cost health care users in Ontario, Canada: Demographic, socio-economic, and health status characteristics. BMC Health Services Research, 14(1), 532. https:// doi.org/10.1186/s12913-014-0532-2

Rosella, L. C., Kornas, K., Yao, Z., Manuel, D. G., Bornbaum, C., Fransoo, R., \& Stukel, T. (2018). Predicting High health care resource utilization in a single-payer public health care system: Development and validation of the high resource user population risk tool. Medical Care, 56(10), e61-e69. https://doi.org/10.1097/ MLR.0000000000000837

Rosella, L. C., O’Neill, M., Fisher, S., Hurst, M., Diemert, L., Kornas, K., \& ... Manuel, D. G. (2020). A study protocol for a predictive algorithm to assess population-based premature mortality risk: Premature Mortality Population Risk Tool (PreMPoRT). Diagnostic and Prognostic Research, 4(1), 1-11.

Shahidi, F. V., Muntaner, C., Shankardass, K., Quiñonez, C., \& Siddiqi, A. (2019). The effect of unemployment benefits on health: A propensity score analysis. Social Science \& Medicine, 226, 198-206. https://doi.org/10.1016/j.socscimed.2019.02.047

Statistics Canada. (2020a). Canadian Economic Dashboard and COVID-19. Retrieved from https://www150.statcan.gc.ca/n1/ pub/71-607-x/71-607-x2020009-eng.htm. Accessed 7 Dec 2020.

Statistics Canada. (2020b). Labour Force Survey, April 2020. Retrieved from Ottawa, ON

Statistics Canada. (2020c). Labour Force Survey, July 2020 [Press release]

Stuckler, D., Basu, S., \& McKee, M. (2010). Budget crises, health, and social welfare programmes. BMJ, 340, c3311. https://doi.org/10. 1136/bmj.c3311

Stuckler, D., Basu, S., Suhrcke, M., Coutts, A., \& McKee, M. (2009). The public health effect of economic crises and alternative policy responses in Europe: An empirical analysis. Lancet, 374(9686), 315-323. https://doi.org/10.1016/s0140-6736(09) 61124-7

Thomas, B., Dorling, D., \& Smith, G. D. (2010). Inequalities in premature mortality in Britain: Observational study from 1921 to 2007. BMJ, 341, c3639. https://doi.org/10.1136/bmj. c3639

Wahlbeck, K., \& McDaid, D. (2012). Actions to alleviate the mental health impact of the economic crisis. World Psychiatry, 11(3), 139-145. https://doi.org/10.1002/j.2051-5545.2012. tb00114.x 
Wiseman, S. M., Crump, R. T., \& Sutherland, J. M. (2020). Surgical wait list management in Canada during a pandemic: Many challenges ahead. Canadian Journal of Surgery, 63(3), E226.

Wodchis, W. P., Austin, P. C., \& Henry, D. A. (2016). A 3-year study of high-cost users of health care. Canadian Medical Association Journal, 188(3), 182. https://doi.org/10.1503/ cmaj. 150064
Wolfson, J. A., \& Leung, C. W. (2020). Food insecurity and COVID19: Disparities in early effects for US adults. Nutrients, 12(6), 1648 .

Publisher's note Springer Nature remains neutral with regard to jurisdictional claims in published maps and institutional affiliations.

\section{Authors and Affiliations}

\section{Emmalin Buajitti ${ }^{1} \cdot$ Laura C. Rosella $^{1,2} \mathbb{D} \cdot$ Kevin Bryan $^{3} \cdot$ Ingrid Giesinger $^{1} \cdot$ Vivek Goel $^{4}$}

\section{Laura C. Rosella}

1 Dalla Lana School of Public Health, University of Toronto, Toronto, ON, Canada

2 Institute for Better Health, Trillium Health Partners, Mississauga, ON, Canada
3 Rotman School of Management, University of Toronto, Toronto, ON, Canada

4 Institute of Health Policy, Management and Evaluation, University of Toronto, Toronto, ON, Canada 